\title{
Directing self-assembly to grow adaptive physical structures
}

\section{Authors}

A. Blaney, J. Alexander, N. Dunn, D. Richards, A. Rennie, J. Anwar

${ }^{1}$ HighWire CDT, Lancaster University, Lancaster, UK

${ }^{2}$ School of Computing and Communications, Lancaster University, UK

${ }^{3,4}$ Imagination, Lancaster University, UK

${ }^{4}$ Department of Engineering, Lancaster University, UK

${ }^{5}$ Department of Chemistry, Lancaster University, UK

a.blaney@lancaster.ac.uk, j.alexander@lancaster.ac.uk, n.dunn@lancaster.ac.uk, d.richards@lancaster.ac.uk, a.rennie@lancaster.ac.uk and j.anwar@lancaster.ac.uk

\begin{abstract}
Additive manufacturing technologies offer exciting opportunities to re- think the process of designing and fabricating physical structures. This paper outlines initial work that seeks to extend existing AM capabilities, creating adaptive structures that can tune their physical properties by exploiting processes of self-assembly and material aggregation. The paper details an investigation of self-organising / self-assembling structures that can respond to different conditions by adapting their physical properties over time, suggesting how this opens up new possibilities for various design and engineering applications (including but not limited to medical implants, prosthetics, product design, aerospace and next-generation architectural designs). The process uses electrolysis of seawater to demonstrate a proof-of-concept of tuneable material structures, via crystal growth. Results gained so far demonstrate an aggregation-based multi-material system that is sensitive to changing environmental conditions. Material properties of grown structures have been analysed and illustrate that different materials can be created from an abundant base material (natural seawater) by manipulating environmental conditions (i.e. electrical current). It is found that turbulence is a useful property within these kinds of systems and that the physical properties of scaffold structures have significant impact in controlling material properties and resolution.
\end{abstract}

KEYWORDS - Self-Assembly, Adaptive Materials, Additive Manufacturing

\section{INTRODUCTION}

Biological structures continually adapt their shape and material compositions to suit environmental demands, maximise available resources and have the ability to heal. These properties are possible because biological materials are not inert. That is, in contrast to traditional manufactured materials, biological materials can adjust their properties "on-the-fly" and self-organise. For example, bone modelling and remodelling [AMGEN, 2012] is a process that tunes the mechanical and material properties (density / strength) of bone over time to address regular physical stresses acting on them. Biological fabrication processes use external forces to inform material deposition [Vogel, 2003], producing extremely multi-functional and materially economic structures.

Manufactured structures, which adapt their physical properties to meet fluctuating demands, could offer exciting new design possibilities. For example, building components that could alter their material properties (e.g. porosity, elasticity, rigidity, density) to meet temporal demands so as to avoid structural failure when new physical loads are introduced; or machine parts that heal themselves when damaged. Adaptive synthetic materials would also open up new possibilities in the fashion industry, such as wearable materials which change colour, or pattern on demand. Finally, tuneable materials would allow radically new medical implants, prosthesis and splints to be designed, whereby the structures tune their prostheses (in real-time) to meet 
unique patient physiology thereby improving comfort, or alternatively could be implanted as medical scaffolds to help re-grow important biological materials such as bone [Howes \& Laughlin, 2012].

This paper will highlight the potential to instil adaptive qualities that are present in biological structures into manufactured ones by fabricating them out of self-assembling / self-organising materials. The key benefits of these adaptive materials / structures would be: (i) Longevity as changing and multiple demands can be accounted for; (ii) Reduction of material waste as resources can be redistributed within the structure / system over its lifetime; and (iii) Scalable fabrication processes that allows logic from digital design processes such as parametric design [Schumacher, 2016] to be embedded within them, which in turn may lead to more complex structures being created [Tibbits, 2012; Tibbits, 2012], which can physically respond and adapt.

An emerging area of architectural design is now exploring how advanced fabrication technologies can be combined with new materials to create adaptive, high-performance designs [Soldevila, Royo, \& Oxman, 2015; Oxman, \& Rosenberg, 2007; Tibbits \& Cheung 2012]. This paper describes ongoing research towards this goal, demonstrating proof-of-concept physical structures that have tuneable adaptive material properties. The paper is structured as follows: firstly, a discussion of work relating to architectural design, synthetic biology and physical computing that uses adaptive and living materials to create structures; secondly, an outline of the experimental method that uses physical computing with crystal formation to build primitive tuneable materials; thirdly, the initial results presented. Finally, a discussion of the findings and suggested opportunities for further work.

\section{BACKGROUND}

Additive Manufacturing ( $A M)$ enables new ways of constructing physical objects with novel material compositions [Oxman, 2011] so that they can fulfil multiple functions [Oxman, Keating \& Tsai, 2011; Oxman et al., 2015], and even respond to external forces by changing shape in useful ways [Guttag \& Boyce, 2015]. Interestingly, AM can also fabricate structures which act as growth media, such as agar. In this way fabricated structures can be coupled with novel materials that grow within these media, allowing material properties to change over time within the defined forms [BioBot 2016; Natalie Alima 2015]. Another approach to creating adaptive materials and architectures utilises synthetic biology [Dade-Robertson, Ramirez \& Zhang, 2014] and chemical systems [Armstrong \& Spiller, 2010; Armstrong, 2014; Hanczyc, 2009]. The former uses bacteria and the latter protocells, which can be programmed to respond to fluctuating environmental conditions, which then alters material properties.

A major challenge for these sorts of systems is how to direct growth processes and build useful structures. Note that in traditional CAD/CAM approaches, digital designs retain great flexibility whilst in the computer, enabling designers to change the shape of structures and/or material properties in real-time, but as soon as the design is physically fabricated, all of the flexible and adaptive behaviour is lost. The designs become fixed and the physical objects do not adapt to changing conditions. In contrast, the huge promise of adaptive tuneable material is that they may enable physical objects to retain the same degree of flexibility, control and adaptability as their digital counterparts.

To explore new approaches to creating adaptive materials for design and engineering applications, selfassembling materials have been incorporated into the fabrication process. Specifically, in this paper the combination of self-assembling crystal materials with AM to achieve adaptive tuneable materials, mimicking bones adaptive and tuneable abilities is proposed.

Mineral accretion [Hilbertz \& Goreau, 1996; Hilbertz 1992] is a process that deposits limestone $\left(\mathrm{CaCO}_{3}\right)$ and / or brucite $\left(\mathrm{Mg}(\mathrm{OH})_{2}\right)$ on cathode structures that are submerged in seawater / brine using the process of electrolysis. Material build-up on the cathode scaffold can be affected by multiple conditions, for example, distance from the anode, electrical current, cathode geometry and fluid flow [Goreau, 2012]. Higher electrical voltages and current values create brucite quickly compared to lower voltages and current producing limestone slowly; altering these conditions over time can create a composite material [Corrie Van Sice 2011].

Self-assembling materials (such as crystal growth) can adapt their physical properties (shape, density, composition, porosity, colour) in response to the physical environmental conditions in which they grow (temperature, $\mathrm{pH}$, voltage). The objective of this research is to prove that by designing and manipulating 
cathode scaffolds, it is possible to direct how crystal structures grow. By carefully manipulating environmental conditions (e.g. electrical current, temperature, $\mathrm{pH}$ of the solution) it is be possible to adapt and tune the deposited material properties (shape / location, volume, growth rate, composition, textures), and these studies may provide important clues for designing powerful AM technologies in the future that operate via directed self-assembly of materials.

\section{METHODS}

Currently, the proposed system uses the mineral accretion process to build adaptive structures that mimic adaptive and tuneable features of biological structures, such as bone. The mineral accretion process is relatively straightforward; a series of cathodes are placed within a seawater solution and then by changing the electrical current, different types of materials (e.g. limestone and/or brucite) are deposited on the cathode scaffolds. The main benefit of this process is that it is robust, low cost (at the laboratory scale) and easy to setup initially. The current system controls material properties (location, volume, rate and type) manually by varying the voltage / current by connecting individual and or multiple cathode elements to be supplied with a fixed or varying voltage over time. This creates a locally "tuneable" environment that informs material aggregation, specifically, the location, volume, rate and composition of the material deposited on the scaffold.

Figure 1 details a basic cathode setup. The cathode incorporates four resistors, which allow different values of electrical current to be present at different parts of the cuboid cathode structure. This cathode was submerged in natural seawater and the combination of adjustable electrical current and the seawater solution enables local control over where material is deposited and its properties (i.e. mix of limestone and brutice).

The paper now present two experiments, which use different cathode designs to control material aggregation in specific ways.

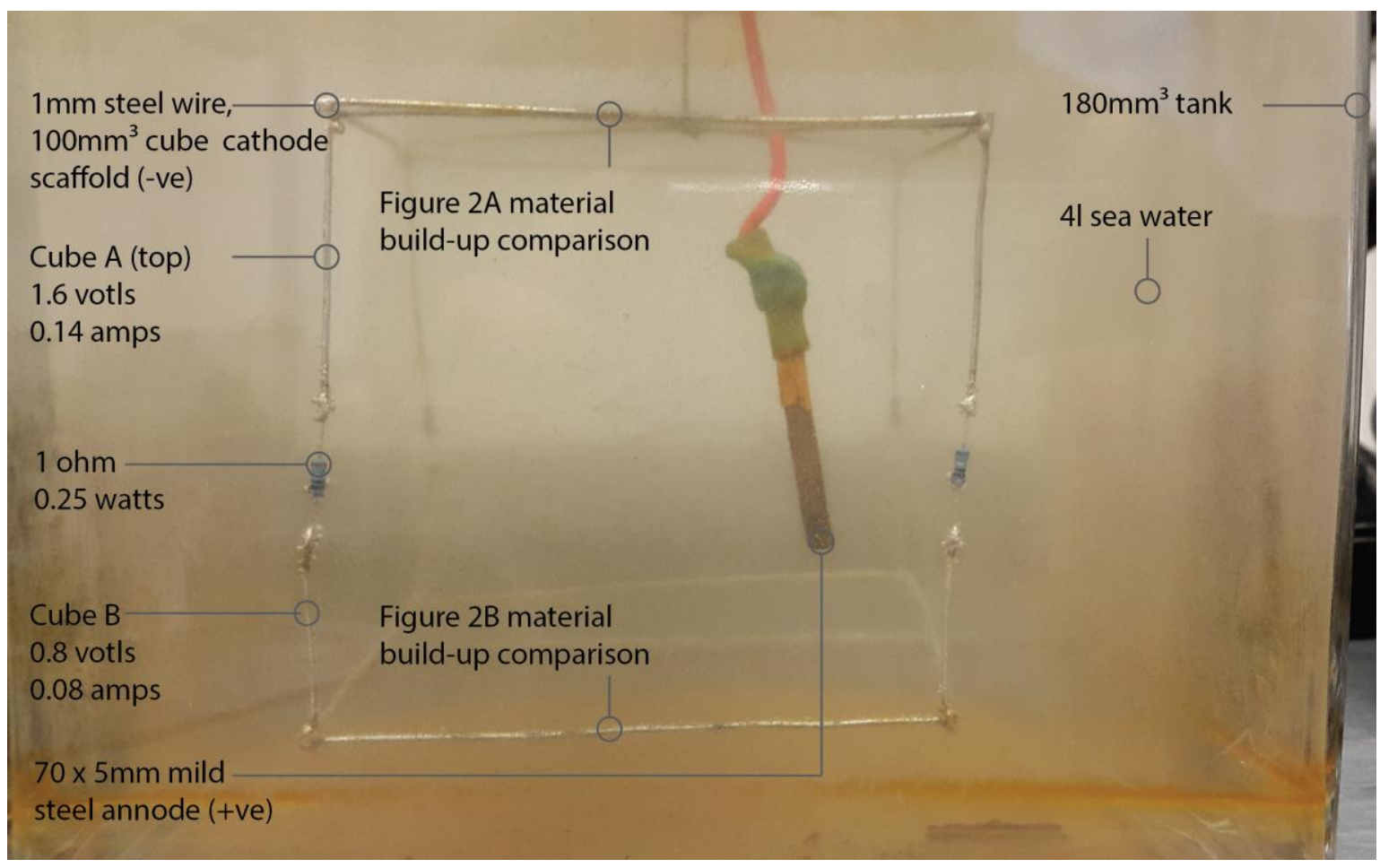

Figure 1. Cuboid cathode with resistors to create two different currents in this configuration. The first experiment was carried out for $\mathbf{2 4 0}$ minutes and material deposition recorded every $\mathbf{3 0}$ minutes. A benchtop power supply unit was used to supply electrical current.

4.

\section{RESULTS}


To test the model, two experiments were performed. The first experiment provides a proof-of-concept that the model can indeed generate multi-material structures via the mineral accretion process, whilst the second experiment shows that material properties can be tuned to create different shapes and material compositions by adjusting controllable parameters such as voltage.

\subsection{Experiment 1: Proof-of-Concept Material Aggregation}

To test that the model is able to generate multi-material structures via the mineral accretion process, the cathode cuboid shown in Figure 1, was submerged in seawater and 1.6 volts and 0.14 amps applied to the top elements of the cube, the resistors then reducing the voltage to 0.8 volts and 0.08 amps to the bottom elements. The system was operational for 24 hours.

It was predicted that more material could accumulate on the top of the cube, and the material would be predominantly brucite as it was supplied with an increased voltage and current which results in the growth of brucite, which grows faster than limestone [Error! Bookmark not defined.Error! Bookmark not defined.]. Similarly, it was expected that the bottom elements of the cube experience less material aggregation, yet the material to be predominantly limestone.

To perform material analysis on the results, a Scanning Electron Microscope (SEM) was used to reveal different material types. Under SEM brucite resembles rosette formations, whereas limestone is shown as needle-like shapes [Error! Bookmark not defined.]. Additionally, fine powder samples from the aggregated materials were analysed using X-Ray Diffraction (XRD) which provided a quantitative measure of the material properties.

Examination of the material deposited on the cuboid cathode revealed that most material accumulated at the bottom (Figure 2B), rather than the top elements as expected. XRD analysis revealed that brucite was more predominant on the top elements of the cube than at the bottom of the cathode structure, as expected, meaning that the different currents did appear to have some effect, yet the overall aggregation process was highly susceptible to the effects of gravity, leading to much more material settling on the bottom of the cube compared to the top parts.
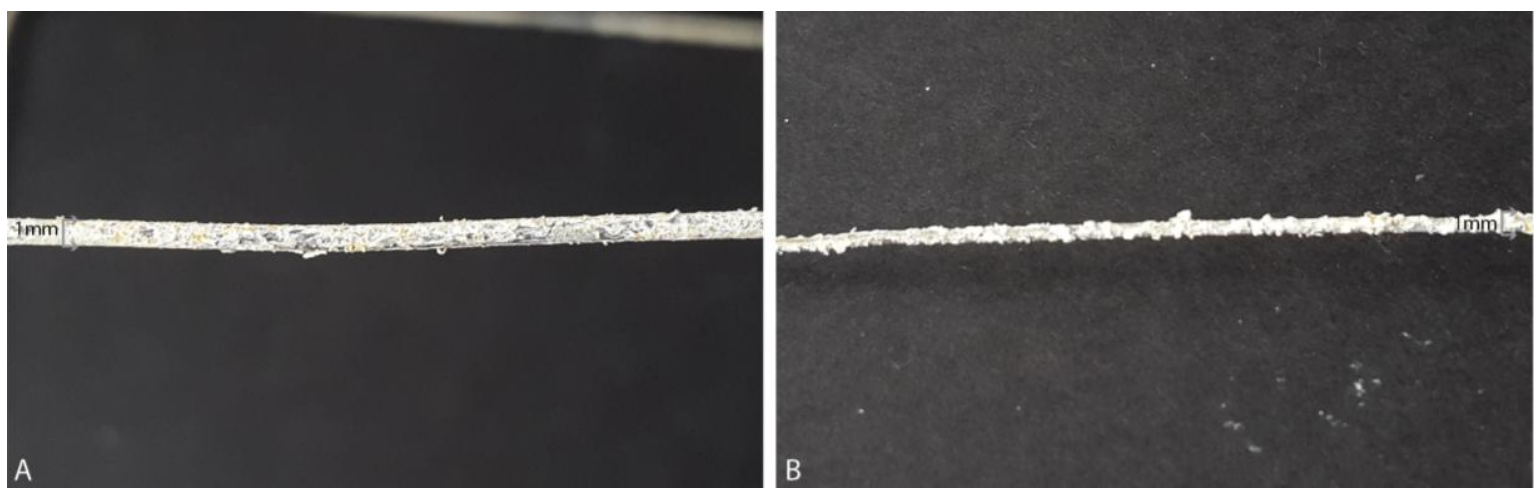

Figure 2 A - Cuboid material build-up top. Top of cube has less material then the bottom. B - Cube material build-up bottom. More material accumulated at the bottom of the cube due to gravity. The wire is $1 \mathrm{~mm}$ in diameter

To improve on these results, three key changes were made to the experimental setup. Firstly, improving the consistency of the seawater solution by dissolving $100 \mathrm{~g}$ of marine salts in $3 \mathrm{~L}$ of water at $25^{\circ} \mathrm{C}$. Secondly, adding an aquarium wave maker to the system to provide agitation of the solution at a rate of $2000 \mathrm{~L} / \mathrm{hr}$. Finally, changing the shape of the cathode setup, testing two further options: (1) where all elements lay on the same plane and resembled a flat fence structure with irregular spacing between vertical elements (Figure 3); and (2) with two individual straight cathode wires which were hung vertically in the seawater tank. The system was once again run for 24 hours, and SEM and XRD material analyses undertaken. 
Figure 3 shows the fence cathode with two material build-ups occurring. Material substance shown on Figure $3 \mathrm{~A}$ is a result of the steel anode dissolving which contaminated the solution. As a result, this material growth predominated after the initial white material. XRD analysis of the porous material substance reveals it is a foreign material as it does not match either the known calcium carbonate or magnesium hydroxide values. Examination of the materials surface in Figure $3 \mathrm{~A}$ revealed a porous quality, which increased as the vertical elements of the fence became closer to one another. The material also began to join together between the closer vertical elements resulting in a solid wall type build-up. The material shown in Figure 3B was initially grown on the fence cathode, as it was revealed when the porous material was removed. Notably, the XRD analysis did reveal that both limestone and brucite were present in the material samples, with limestone being more predominant, which suggests that a multi-material structure could indeed be built with some modification to the cathode structure.

Figure 4 shows the two individual straight cathode wires which were analysed by way of SEM. The SEM analysis from a portion of a wire reveals varying amounts of limestone and brucite, which was dependant on the location of where the material analysis was undertaken. Interestingly, this revealed that the purity of the cathode material also affects material type deposited, because it influences the electrical current uniformity. This finding suggests that altering the current value within the cathode scaffold controls the material type deposited. However, the results from the cuboid cathode experiment also suggest that agitating the solution is the overriding factor to control material location, rate and volume deposited. Examination of the fence cathode found that agitation counteracted the effects of gravity and created a more uniform material deposition (Figure 3).

Finally, Figures 5 and 6 present the data from these experiments. Figure 5 shows the material composition by way of SEM analysis of the two straight wire cathodes, which reveals the varying amounts of limestone and brucite build-up that occurred in two different locations. The varying material composition was a result of the non-uniform material properties of the wires which created varying electrical currents over its surface. Figure 6 then compares XRD values of the material build-up taken from the cube and fence cathode to known values for limestone and brucite. These results establish proof of concept that it is possible to govern material properties of the mineral accretion process. This was achieved by physically manipulating the environment in which the materials grow (voltage and agitation) as well as altering the cathode scaffolds properties on which the material was deposited.

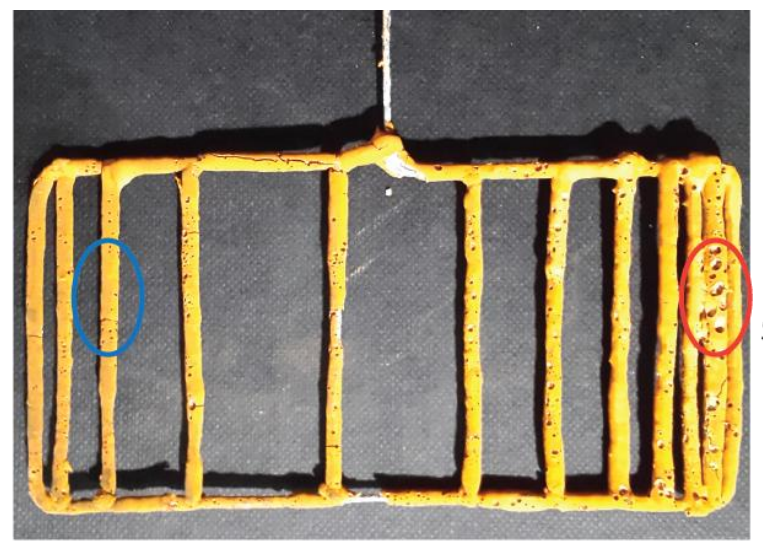

A

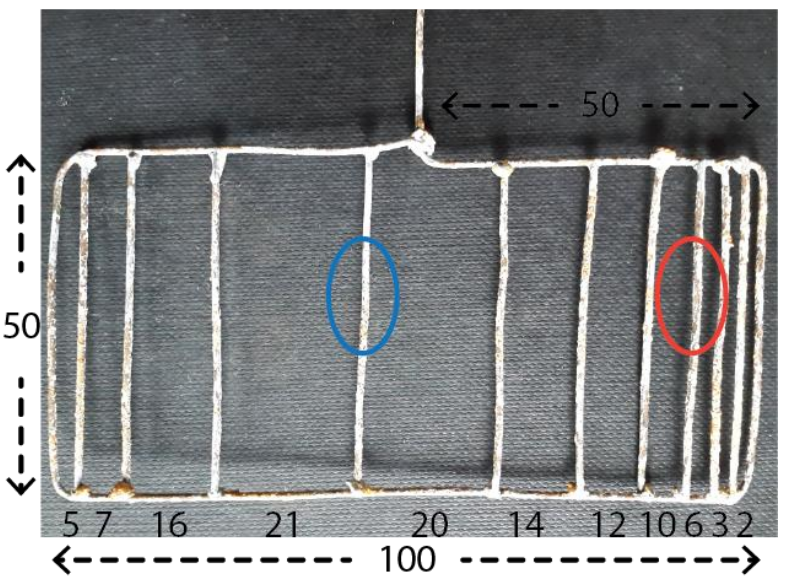

B

Figure 3. A - Cathode shape informs material properties deposited. The substance on Fig $4 \mathrm{~A}$ is created from the dissolved anode (iron oxide). B - Initially a uniform material comprised of limestone and brucite was deposited but then inhibited as the dissolved anode material predominated. All units in $\mathrm{mm}$. $1 \mathrm{~mm}$ diameter steel wire used to make the cathodes. 


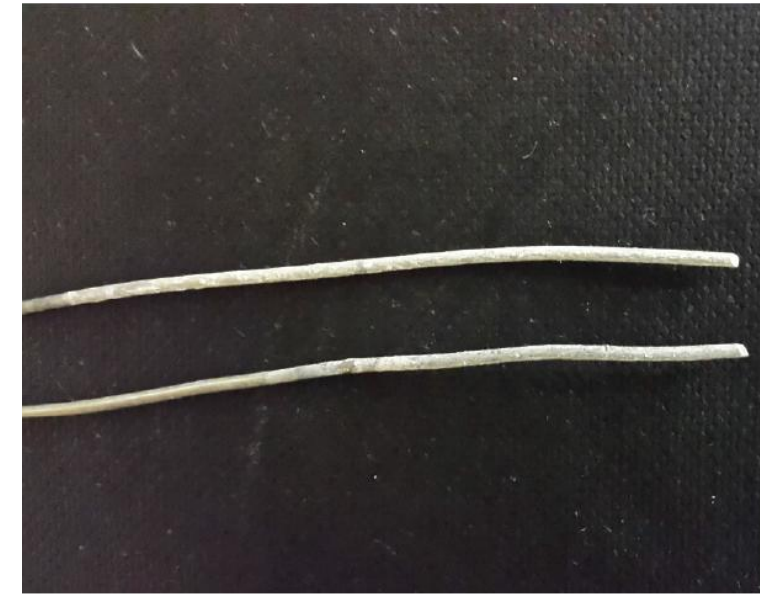

A

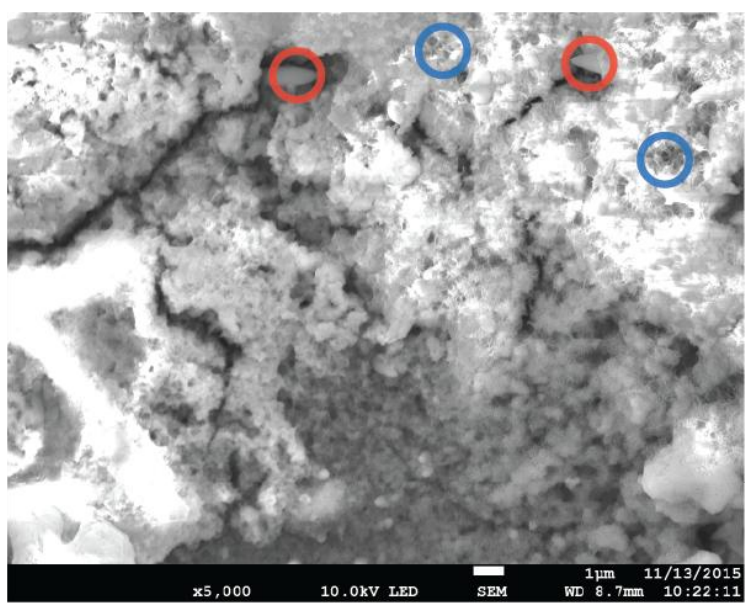

C

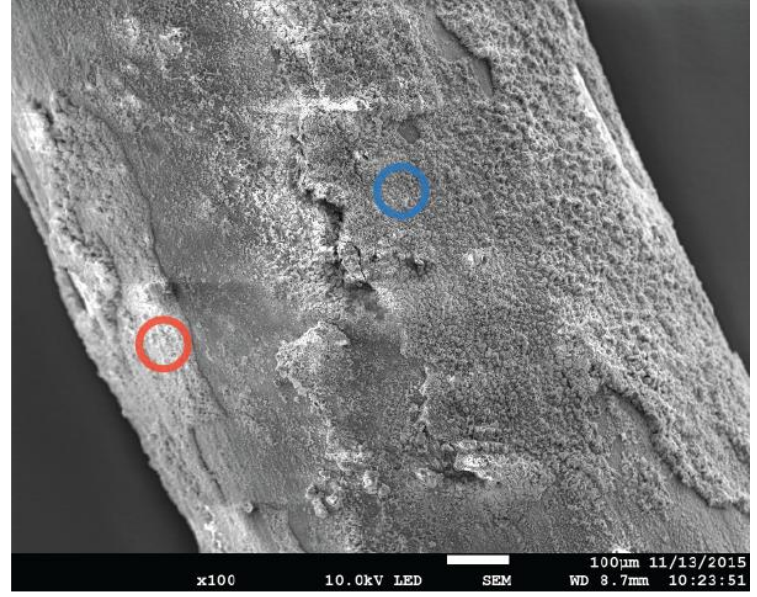

B

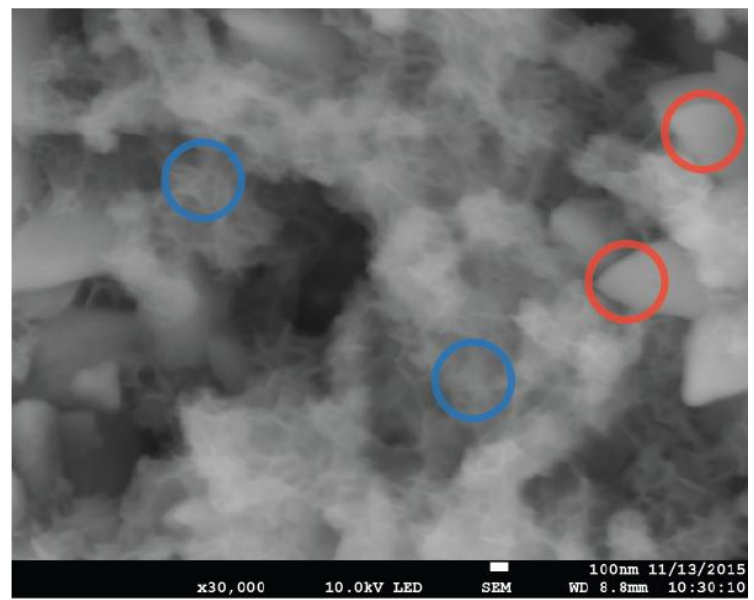

D

Figure 4. A - Cathode wire to test material build-up using SEM. B - SEM revealed effects of the cathodes purity as varying amounts of brucite and limestone crystals depending on analysis locations. C, D Brucite highlighted with red circles compared to the limestone highlighted with blue circles. $100 \mathrm{x}$ $1 \mathrm{~mm}$ diameter steel wire cathode used. 


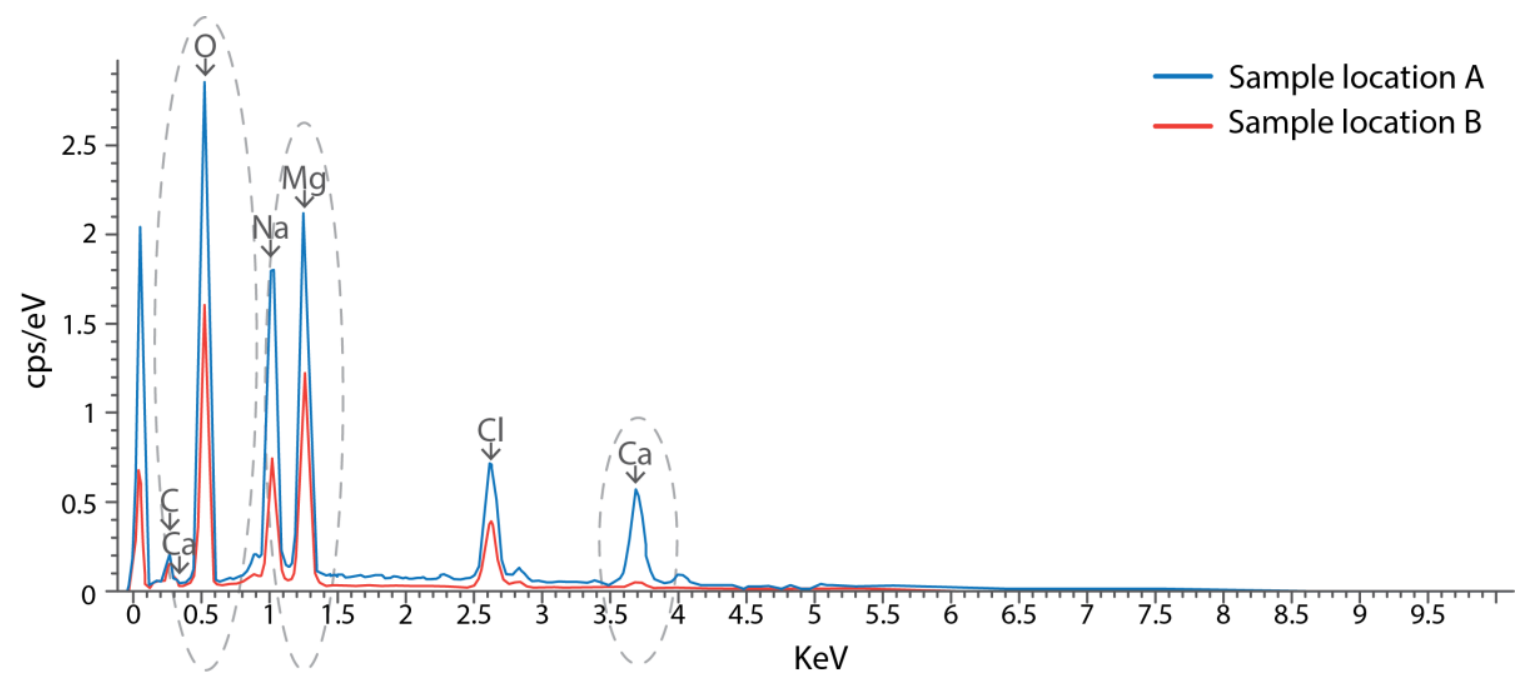

Figure 5. SEM analysis of two wire cathodes reveals varying amounts of brucite and limestone depending on analysis location. This establishes the effects of the cathodes purity (how uniform the electrical current is) on material type. This establishes a multi-material system is achievable using this process by fluctuating current.

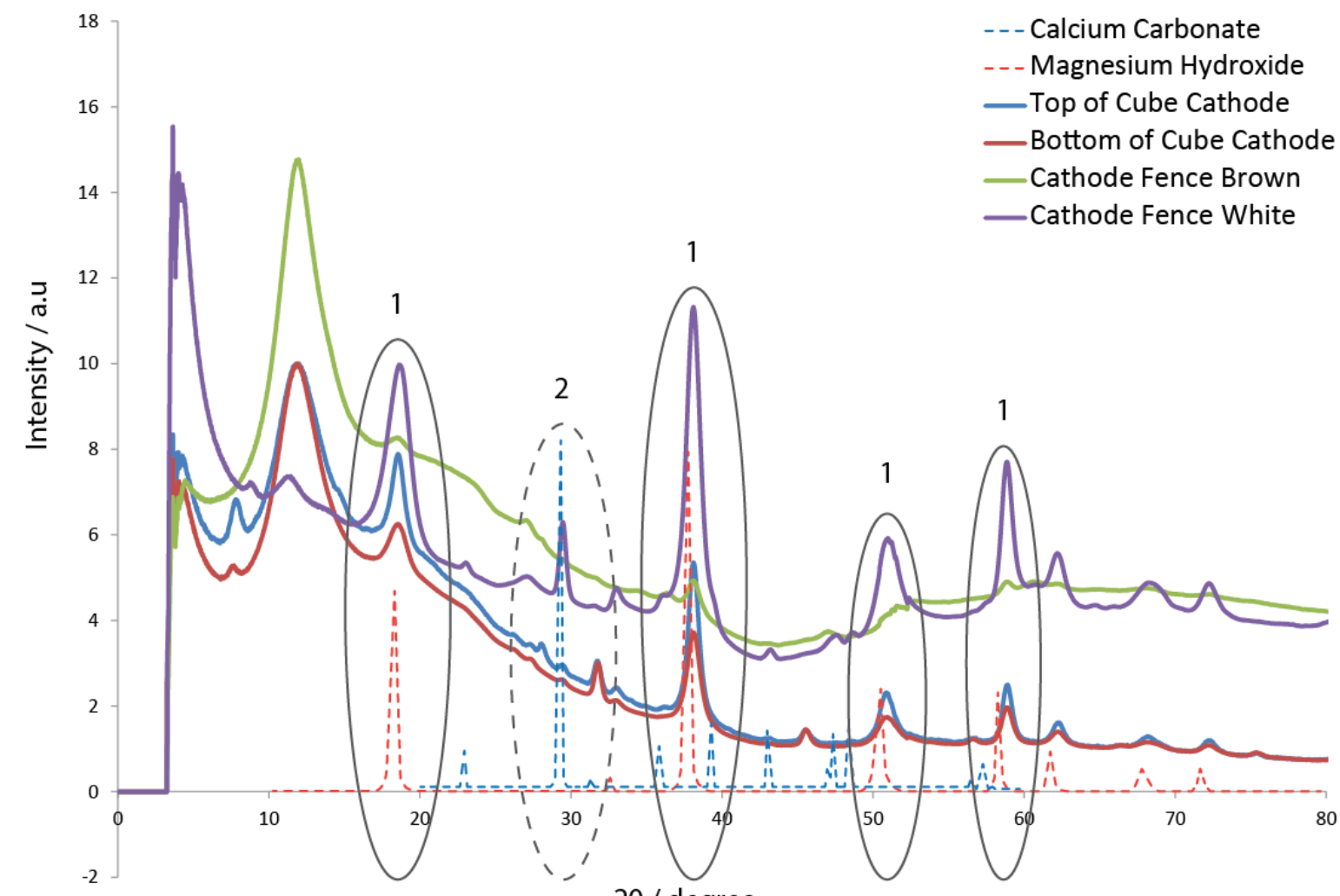

$2 \theta /$ degree

Figure 6. XRD of samples compared to $\mathrm{CaCO}_{3}$ and $\mathrm{Mg}(\mathrm{OH})_{2}$. The cube cathode strongly resembles $\mathrm{Mg}(\mathrm{OH})_{2}$ values (circles with 1), demonstrating that the cube cathode typology allows limited control. Whereas analysis of the white fence cathode demonstrates that both material types are created (circles with 1 and 2), and therefore by controlling electrical current, it is possible to tune material properties within a range. 


\subsection{Experiment 2: Tuneable Materials on a 2D Grid}

To extend the proof-of-concept study and demonstrate that simple shapes and material composition can be controlled via material aggregation and directed self-assembly, a 6x6 2D grid of conductive elements (Figure 2) was used to grow a specific shape with varying material thicknesses. The effects of varying voltages supplied to individual elements on the grid will determine its effect on material composition at defined locations.

Figure 7 describes the $6 \times 6$ 2D cathode grid, which is made up of physically separated cathode elements ( $1 \mathrm{~mm}$ copper wires). Material build-up on the grid cathode is manually controlled by connecting individual elements or multiple elements (via a breadboard) to a bench power supply. The conductive copper wires (i.e. the cathode) are held in place using modular components, which were fabricated in insulating nylon with AM (using the Selective Laser Sintering process). The modular supports are used to physically separate the copper wires and allow specific electric currents to be applied across the $6 \times 6$ gridded cathode structure.
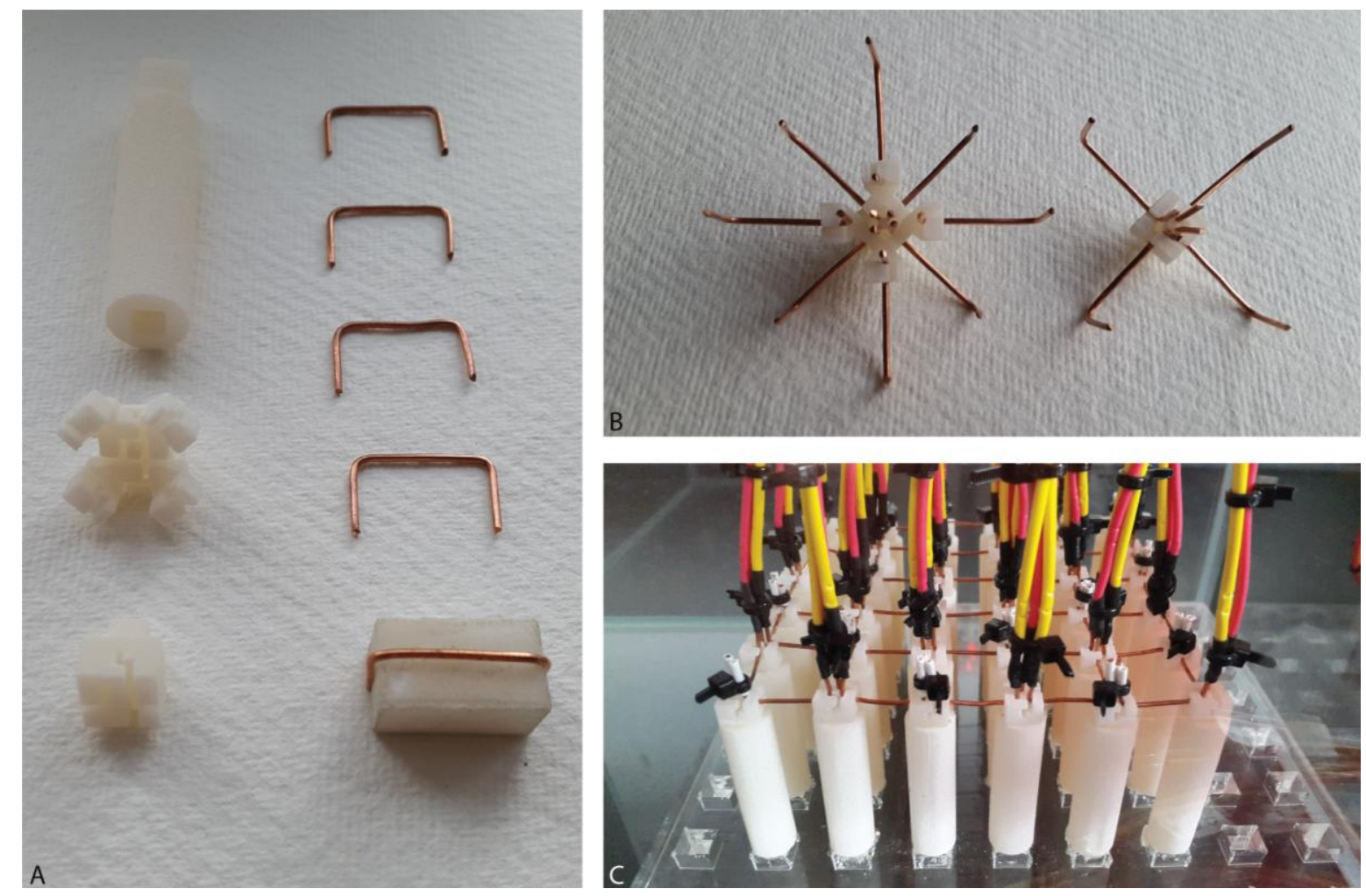

Figure 7 A - AM was used to fabricate modular nodes made to physically separate the cathode elements. B Two different head were fabricated to increase the resolutions of the grid. C - Final 2D 6x6 grid

To test that it is possible to control material properties of resulting structures, different elements within the $6 \times 6$ cathode grid were provided with different voltages in order to create a heart shape (Figure 8). Half of the heart shape was supplied with 4.7 volts at one time while, once the growth time was complete the other half was supplied with 3.0 volts. The intention of this experiment was to determine whether it is possible to indirectly create a specific shape with varying material thickness and what effect varying voltages has on growth rate when using the mineral accretion process.

To examine growth rate of materials under different conditions (e.g. 3 volts compared to 4.7 volts), one cathode element was disconnected every 3 hours for the supplied with 3.0 volts (Figure 8 ), and every 2 hours for the half supplied in 4.7 volts similarly shown in Figure 8 . The value of 3 hours was chosen because initial tests found that it takes 3 hours, at 3.0 volts to grow enough material to be visible with the human eye. Once all of the elements that were supplied with 3.0 volts had finished growing, the wires to be supplied with 4.7 volts were connected to grow the other half of the intended heart shape. To determine the effects that varying voltages and currents have on material composition (i.e. percentage amount of limestone compared to other materials present and growth rate), 12 wires were supplied with different voltages, each individual element being supplied with a set voltage for 2 hours (Figure 8). 
This cathode design should provide a clear heart shape (on the elements supplied with 3.0 and 4.7 volts in Figure 8) with different sides of the heart shape growing at different rates and thicknesses. It was expected to see a faster rate of material growth occurring on the half supplied with 4.7 volts, with more material aggregation on elements that are supplied with electricity for longer periods of time.

Notably, as discovered in the first experiment, agitation of the seawater solution is important to resist the effects of gravity as materials self-assemble. Consequently, an initial test on the $6 \times 6$ grid agitated the solution every 30 minutes using the aquarium wave maker system. However, from these tests it was found that agitation of the solution with the grid-shaped cathode structure produced detrimental effects to early growth of crystals, causing grown material to fall off the structure during agitation intervals. To counteract this tendency, this experiment did not use agitation to counteract gravity as material was growing, however, for this experiment, it was believed that the effect of gravity would be less significant because all of the individual elements lie within the same plane (i.e. the grid is flat). Interestingly, it is believed that control of agitation may be a useful parameter for preventing and even reversing material growth in future work.

The experiment ran for a total of 67 hours: 27 hours for the elements supplied with 3.0 volts, 18 hours for the elements supplied with 4.7 volts and 22 hours for the elements supplied with varying votlages. $300 \mathrm{~g}$ of marine salts were dissolved in $6.5 \mathrm{~L}$ of water and the $2 \mathrm{D}$ cathode grid was then submerged within the solution. Once the first half of the heart shape was grown (3.0 volt elements) the cathode was carefully taken out of the solution, the solution was then agitated for 1 minute and the cathode grid returned and the other half of the heart shape was grown (4.7 volts elements). A new solution was made before carrying out the experiment which supplied elements with varying voltages. Two carbon anodes of radius $6.3 \mathrm{~mm}$ and length $75.0 \mathrm{~mm}$ were used, because the carbon anodes do not dissolve and contaminate the solution and should not affect the material build-up.

In contrast to the first experiment, which used SEM and XRD methods to perform material analysis, this time $X$-Ray Fluorescence (XRF) was used to analyse the results of this test. XRF was used as it provides a detailed percentage breakdown of different materials present of the cathode elements. XRF determines the material composition on a small location of the individual cathode elements, as such it may not provide a complete analysis of the whole material composition. XRF analysis was also used as it is much faster than XRD and SEM. To compare growth rates, the radius of material aggregation on each element was measured using a digital Vernier.

\subsection{RESULTS}

The paper firstly compares the shape of the grown heart with the intended shape, and then the paper explores the physical properties at different parts of the design.

\subsection{Experiment 2: Growing a Defined Shape}

Figure 9 shows the completed growth of the heart shape. Growth is shown here by the lighter material, the darker material being a result of the copper oxidising. Examination of the material growth reveals a clear heart shape was achieved with the half supplied with 3.0 volts, the half supplied with 4.7 volts also predominantly grew where it was intended which completed the heart shape, however one cathode element (wire 6DB) had unintended growth occurring on it when carrying out the growth of the 4.7 volt elements. The unintended growth may be due the material growth occurring on the intended wire contacting a neighbouring wire and inducing unintended growth. If this is the case redundancy is required. Introducing redundancy will be able to reverse material growth which occurs on unintended elements. The unintended growth may also be a result of neighbouring wires contacting one another, this can be addressed by fabricating the scaffolds using AM technology, which affords increased tolerances. The elements supplied with 3.0 volts which were supplied with electrical current for longer resulted in increased material build-up, this was also the case for the elements supplied with 4.7 volts apart from the last element (wire 6FD). The anomaly may be a result of material continually decaying away from this cathode element during growth, this would suggest the way the materials fabricate themselves is not linear when voltage / turbulence is increased.

\subsection{Experiment 2: Localised Material Properties}


The primary objective was to grow a predefined heart shape on the $2 \mathrm{D}$ grid that had varying material volumes. The heart shape was successfully grown. Additionally, various material properties appeared on the individual elements of the heart shape, and also the elements supplied with varying voltages over time, this highlights that both time and environmental manipulations can result in increased control over material properties. The findings are revealed from examination during material growth phase and the resultant structures from material growth (Figure $9-13$ ).

Figure $10-11$ show plots of material deposition over time. Figure 10 reveals material deposition increased for both voltage values ( 3.0 and 4.7 volts) respectively the longer they were supplied with electrical current, this establishes control over the amount of material grown at a specific location. Interestingly more material volume and deposition occurred with the elements supplied with 3.0 volts, which were not the expected result due to the lower voltage, this suggests that introducing more turbulence during early stages of material deposition has a detrimental effect. Increased turbulence in this case was a result of increasing voltages, this resulted in an increased amount of hydrogen being produced at the cathodes which appears to have prevented material deposition. Interestingly the growth rate for both voltages (3.0 and 4.7 volts) are quite similar, which both increase over time.

The ability to grow increasing amounts of various materials at increasing rates in specific locations enables the structures to adapt at a faster rate regarding material location. Figure 11 shows an initial trend of increasing material growth amount corresponds with increasing voltages between $3.6-4.5$ volts (0.05 - 0.11 amps), this then falls off. Comparing growth rate (Figure 11) with the material composition (Figure 12) produced from varying voltages reveals that most material deposition occurred if the presence of Chlorine remained below 15 percent. As Chlorine rose to over a threshold of 15 percent the material became more fragile, this was determined by reduced or no material deposition being recorded in these samples. Figure 12 reveals XRF analysis of the cathode elements supplied with varying voltages, the analysis highlights that material composition and functionality can be tuned by manipulating the environment (voltage).

The paper now discusses the four material properties and behaviours observed during this experiment.

Firstly, varying surface textures on the heart shape elements supplied 3.0 volts. A smoother texture was produced on elements supplied with electrical current for longer periods of time, this is compared to an initially granular texture produced from shorter periods of time. A uniform surface texture was created on the of the heart shape supplied with 4.7 volts (Figure 9). Control of surface textures can be tuned to increase surface area, which could result in surface ornamentation of architectural structures.

Secondly, uniform material growth on the cathode elements was achieved on the 3.0 volts elements that were supplied with electrical current for shorter periods of time (up to 15 hours). On these elements supplied with electrical current for longer periods material build-up became more predominant at the bends of the cathode elements. Non-uniform material growth on the 4.7 volts elements was created as the majority of the material build-up occurred at the bends of the cathode elements. Interestingly this allows an increase in control over localised material properties to emerge on individual cathode elements. Initial smooth surface textures can be grown at specific bends / locations and then more granular materials created between these materials, this incorporates both time and environmental manipulations which can govern material properties.

Thirdly, material decay was observed during and after material growth (Figure 13), this was most significant as the voltages increased, at this point an increasing amount of material would deteriorate away from the cathode elements and build-up on the base of the jig and tank. The ability to reverse or remove material from cathode elements introduces redundancy within the system, this maintains control of material growth location if material growth produced on one element contacts a neighbouring element and initiates growth.

Finally, varying mechanical strengths and compositions were achieved by varying voltages supplied to the cathode elements, this was determined by XRF analysis (Figure 12). As voltage increased the amount of calcium present in the material was reduced resulting in an increasingly fragile material. Elements supplied with more voltage appeared very fragile upon examination (Figure 13), this was revealed as the material deteriorated once it was taken out of the tank as a result of the solutions surface tension, this establishes that varying material qualities and functionalities can be achieved by altering the environment (voltage) as materials grow. 


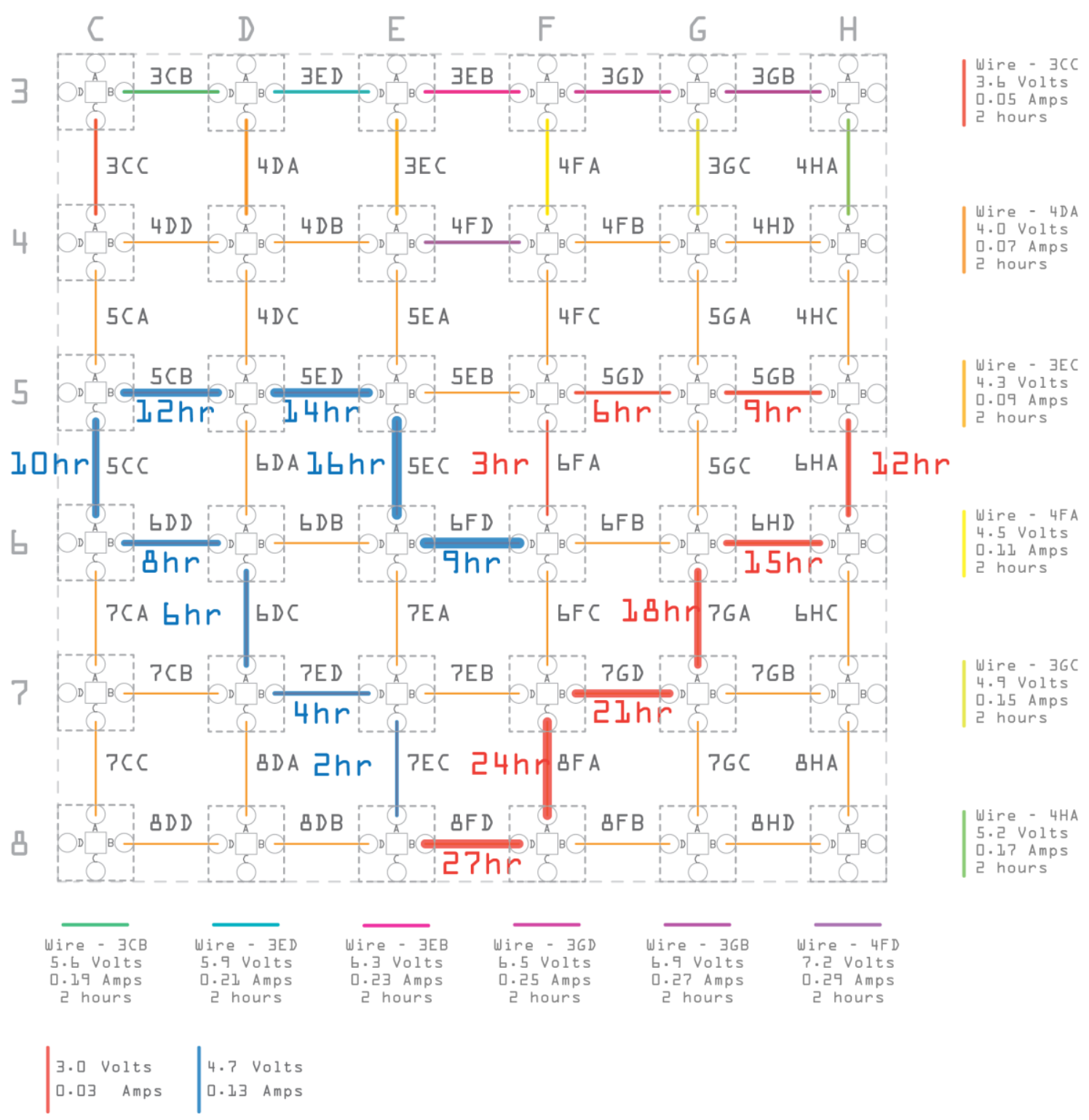

Figure 8. A heart shape is drawn on the $6 \times 6$ grid with the corresponding wire reference to be connected. The heart shape is split in two and supplied with different voltages, each element of the heart is grown for varying time periods. Individual elements are supplied with varying voltages to determine its effects on material composition and properties. 

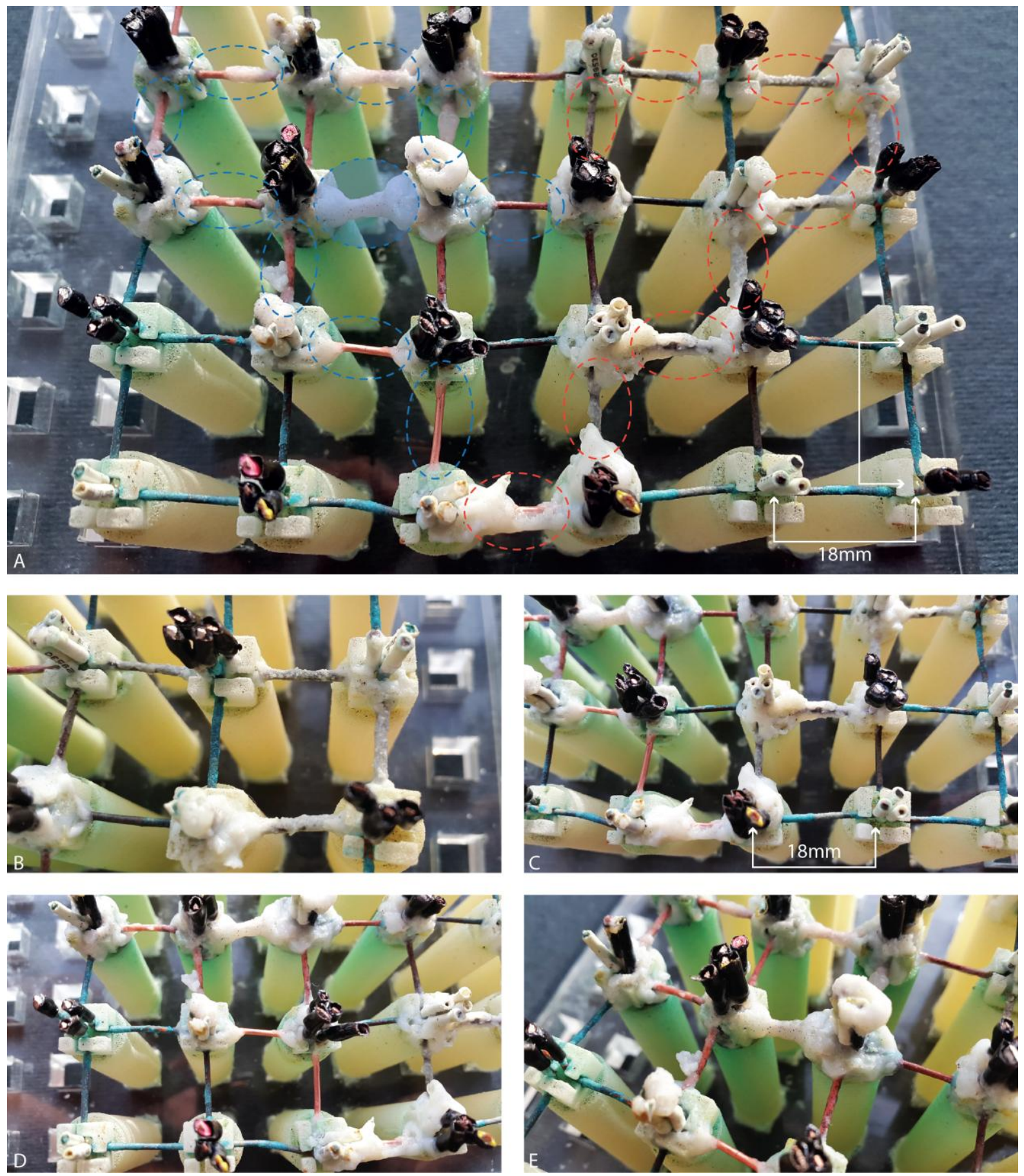

Figure 9. A - The final heart shape growth reveals material growth location and amount can be controlled. B and $C$ - reveals varying surface textures and varying growth location over time when supplied with 3.0 volts. $\mathrm{D}$ and $\mathrm{E}$ - reveals a smooth surface texture was produced with initial growth predominating at the bends which became more uniform over time when supplied with 4.7 volts. 


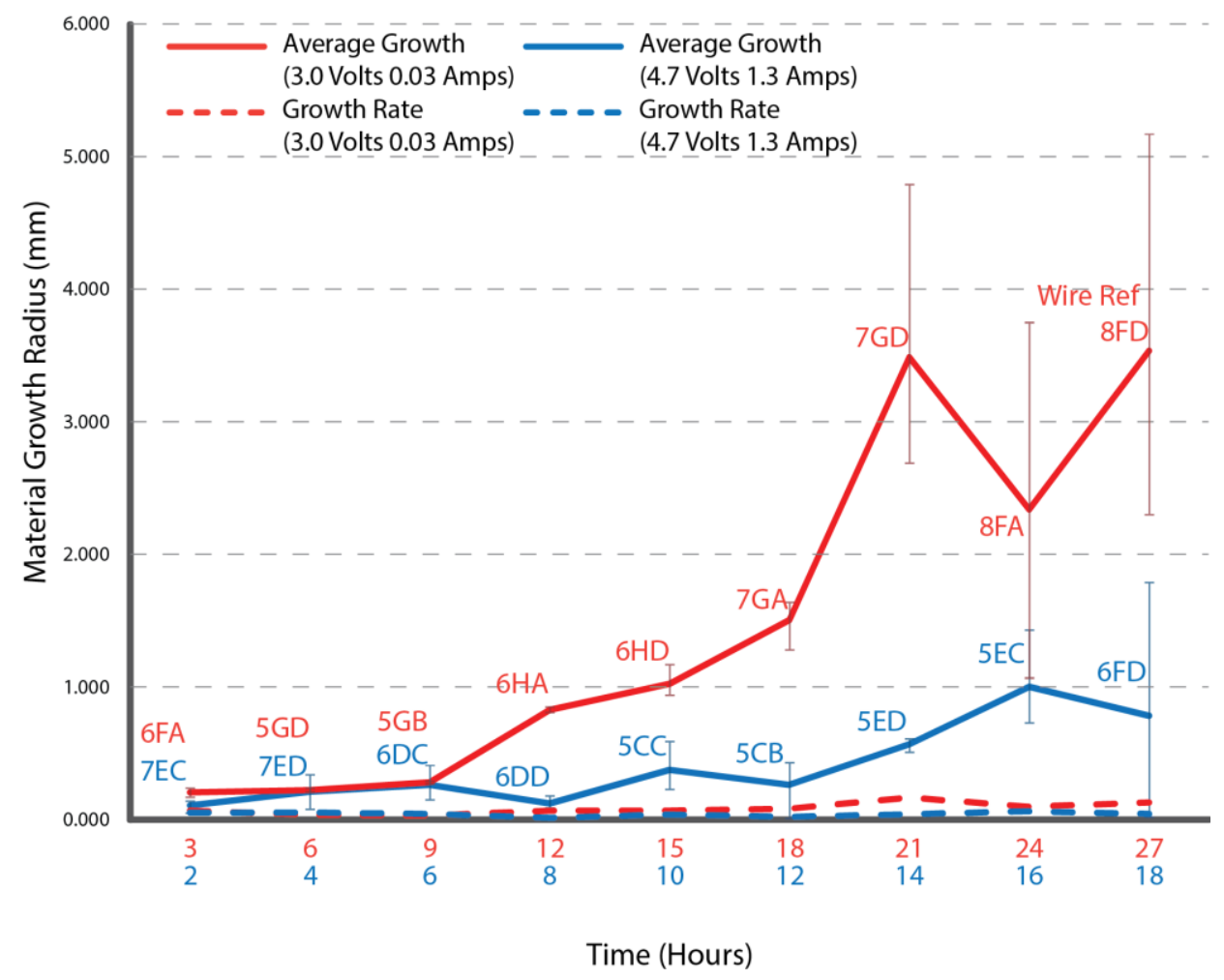

Figure 10. Reveals the growth volume and rate increases for both 3.0 and 4.7 volts the longer the cathode element is supplied with electrical current. Error bars highlight the range between average growth and minimum and maximum growth at point on each cathode wire.

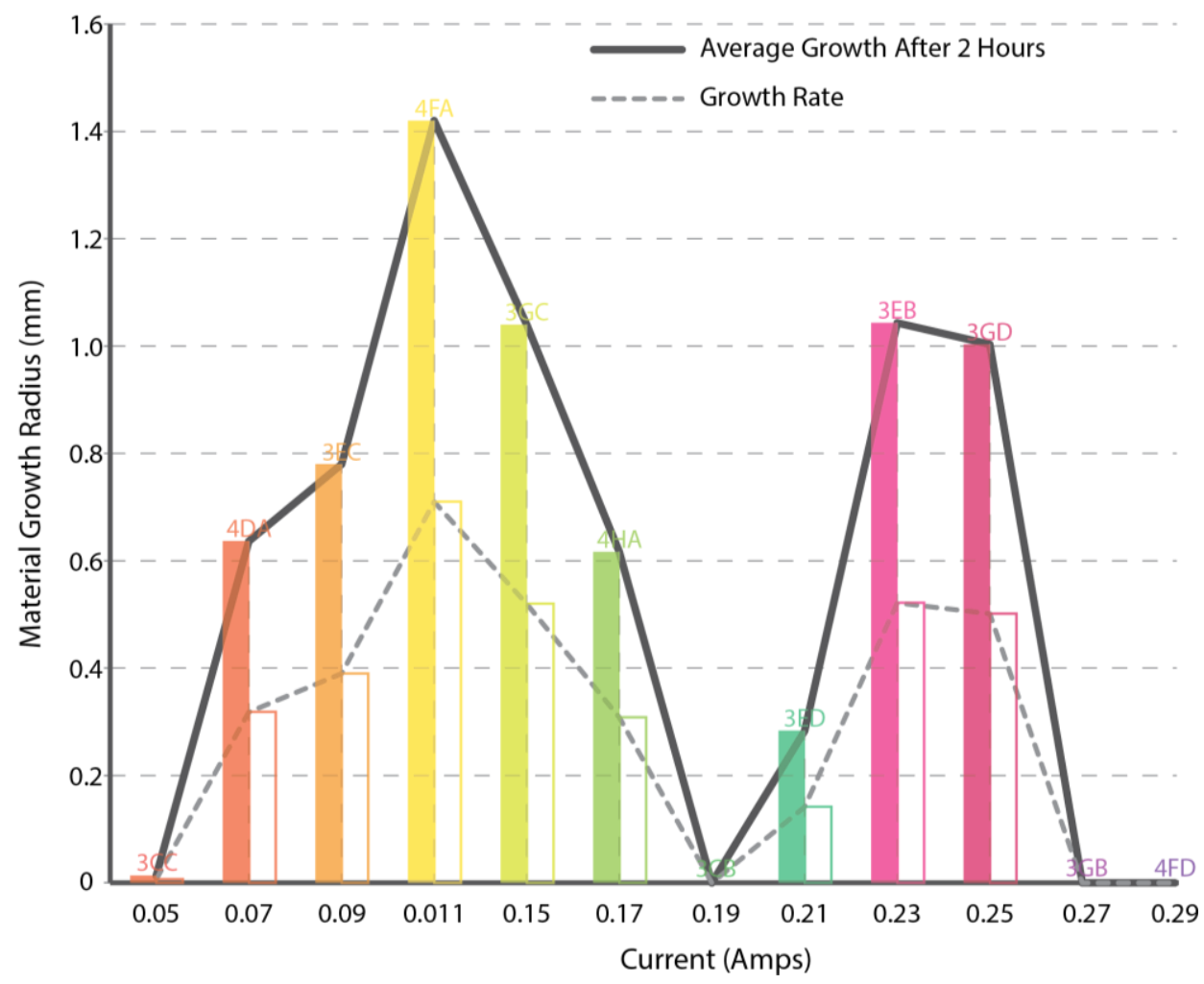

Figure 11. Reveals an initial trend that material growth amount and rate increases as voltage / current increases but cannot be sustained due to the materials increasing fragility. 


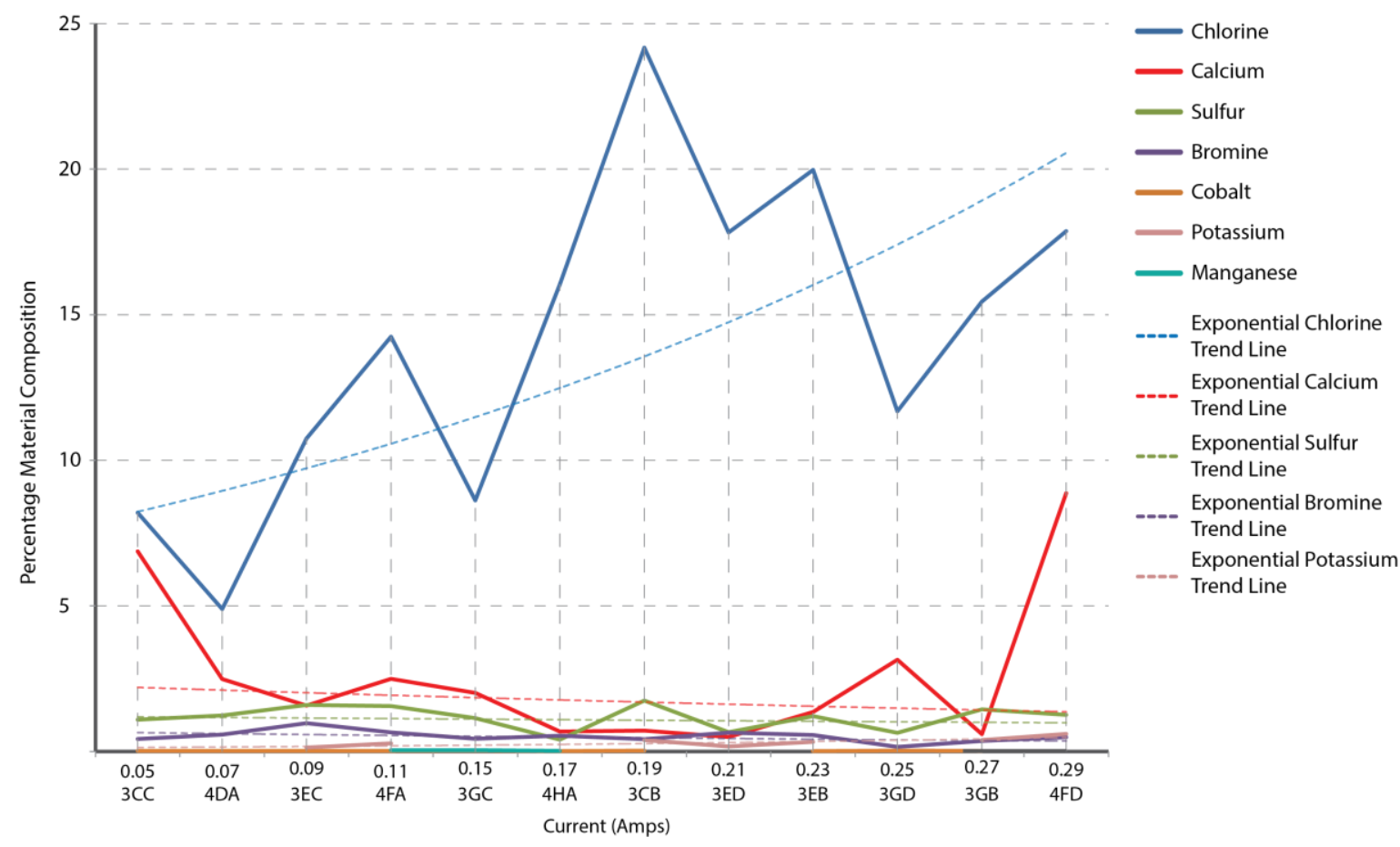

Figure 12. XRF analysis of the elements supplied with varying voltages reveals that the material composition can be tuned by varying voltages. An increase in voltage results in an increase in chlorine with the reduction of all other materials.
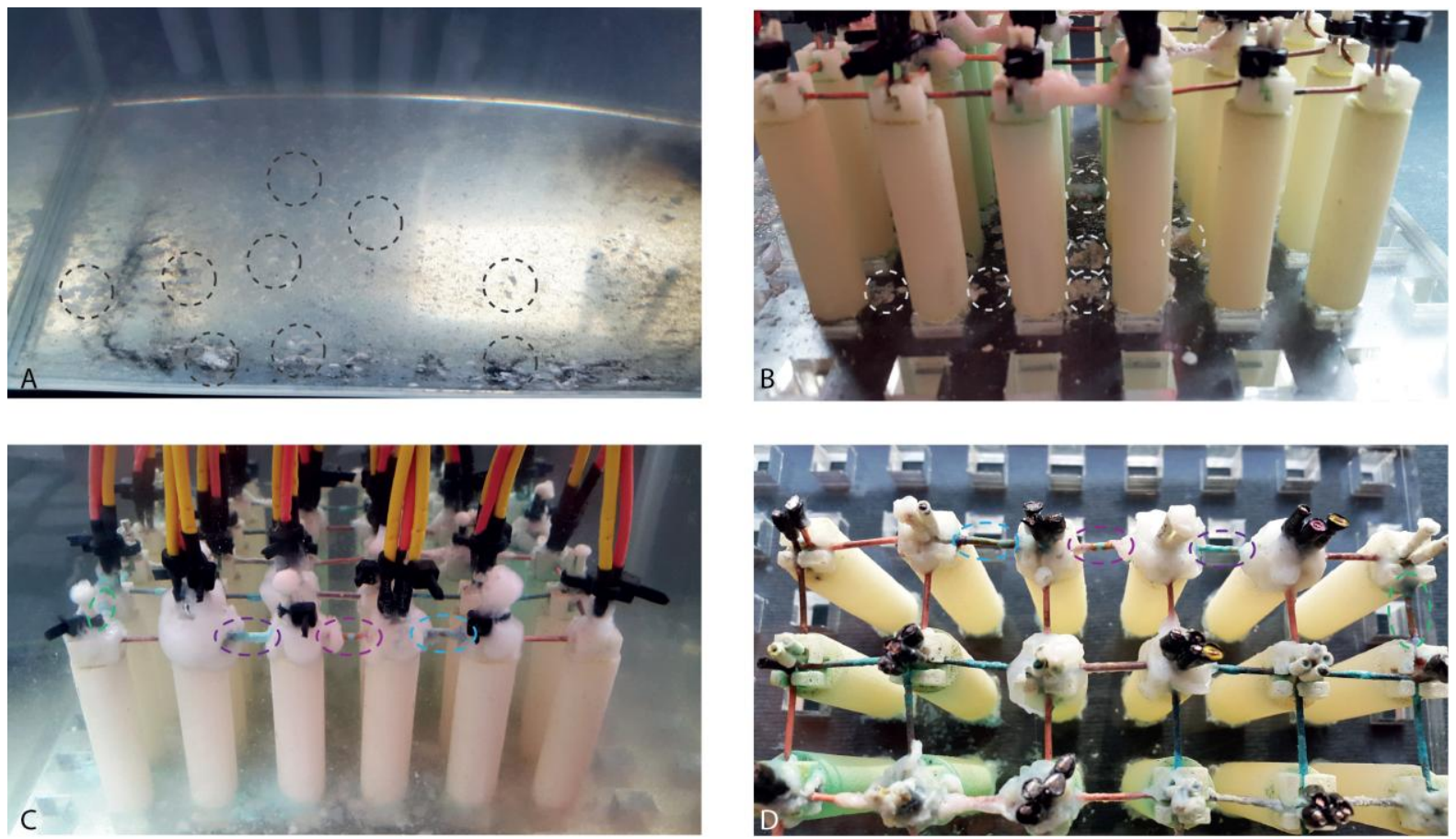

Figure 13. A and B - material growth would decay away from the cathodes elements as it grew. C and D material decay became more apparent as the voltages increased.

5.

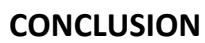

This research represents initial steps towards an ultimate goal of creating truly adaptive physical structures, demonstrated by the results using the mineral accretion process. XRD analysis of the fence cathode demonstrates that it is possible to create a multi-material system with this approach (Figure 3 and 6). The SEM analysis of the two individual wire cathodes shows that varying electrical current controls the material type 
deposited (Figures 4 - 5). Finally, the $6 \times 6$ grid study demonstrates control over material placement and composition by varying electrical current to modify crystal growth. Significantly these results obtained establish it is possible to grow structures from an abundant base material (seawater), which can tune and adapt multiple material properties (shape, composition, volume, location, rate, texture) by imposing external stimulus (voltage, $\mathrm{pH}$, solution agitation) upon the environment in which they grow.

By growing structures through aggregation two major benefits are achieved. Firstly the structures can be grown within a 3D matrix scaffold which can change shape and material properties globally or locally. Secondly the fabrication process is scalable as the material deposited on the scaffolds is based on the materials scale, this is because the molecules that make up the deposited material self-assemble.

Further work could explore the use of design simulations to govern environmental manipulations (voltage amount, voltage location and gradient electrical currents) through hardware to automate the fabrication process. Automating the fabrication process may enable (A) logic from digital designs to be instilled within the fabrication process and resultant physical structures. (B) Adaptive, flexible and tuneable capacities of design simulations to be physically instilled within the structures (i.e. structures fabricated within the constraints of a 3D cathode matrix could change shape and material properties). (C) Increasingly complex structures could be fabricated by imposing multiple design demands, which results in integrated structures [Wiscombe, 2012; Wiscombe, 2010] and multi-functional materials [Oxman, 2012] being created. Notably, this paper shows proof-of-concept that material properties can be tuned (material volume, surface texture, composition) over time through environmental manipulations (voltage), and that this enables functionally graded materials and structures [Richards \& Amos, 2014; Richards \& Amos, 2014] to be fabricated. (D) A continual discourse between design, fabrication and materials could be achieved in real-time.

\section{ACKNOWLEDEMENTS}

Thank you to Nathan Halcovitch and Sara Baldock for carrying out the material analysis. This work is funded by the Digital Economy programme (RCUK Grant EP/G037582/1), which supports the HighWire Centre for Doctoral Training. (http://highwire.lancs.ac.uk). 


\section{REFRENCES}

AMGEN (2012) Bone Biology. Available at: http://bonebiology.amgen.com/index.html?scene=2 (access 18 July 2015).

Armstrong, R. (2014) 'Designing with protocells: applications of a novel technical platform', Life, Vol. 4, No. 3, pp.457-490.

Armstrong, R. and Spiller, N. (2010) 'Living quarters', Nature, Vol. 467, No. 7318, pp.916-918.

BioBot Danny Cabrera (2016) 1 a desktop 3D bioprinter. Available at: http://www.biobots.io/ (access 08 October 2015).

Corrie Van Sice Contributor (2011) Designed Morphologies: Overview of Early Experiments. Available at: http://itp.nyu.edu/ cvs245/Blog/?p=839 (access 01 August 2014).

Dade-Robertson, M., Ramirez, C. and Zhang, M. (2014) 'Material ecologies for synthetic biology: biomineralization and the state space of design', Computer-Aided Design, Vol. 60, pp.28-29.

Goreau, T. (2012) Marine Electrolysis for Building Materials and Environmental Restoration, INTECH Open Access Publisher, Global Coral Reef Alliance, Cambridge, Massachusetts, USA.

Guttag, M. and Boyce, C. (2015) 'Locally and dynamically controllable surface topography through the use of particle-enhanced soft composites', Advanced Functional Materials, Vol. 25, No. 24, pp.3641-3647.

Hanczyc, M. (2009) 'Protocells as smart agents for architectural design', Technoetic Arts, Vol. 7, No. 2, pp.117-120.

Hilbertz, W. (1992) 'Solar-generated material building seawater as a sink for carbon', Ambio, Vol. 21, No. 2, pp.126-129.

Hilbertz, W. and Goreau, T. (1996) Method of Enhancing the Growth of Aquatic Organisms, and Structures Created Thereby, U.S. Patent No 5,543,034.

Howes, P. and Laughlin, Z. (2012) Material Matters: New Materials in Design, Black Dog Pub Limited, pp.104.

Natalie Alima - Bio Scaffold (2015) The Architecture of decay. Available at: http://materiability. com/bio-scaffold/ (accessed on 04 August 2015).

Oxman, N. (2011) 'Variable property rapid prototyping', Virtual and Physical Prototyping, Vol. 6, No. 1, pp.3-31.

Oxman, N. (2012) 'Programming matter', Architectural Design, Vol. 82, No. 2, pp.88-95.

Oxman, N., Keating, S. and Tsai, E. (2011) 'Functionally graded rapid prototyping: innovative developments in virtual and physical prototyping', Proceedings of the 5th International Conference on Advanced Research in Virtual and Rapid Prototyping, Leiria, Portugal, 28 September-1 October, 2011, pp.483-490.

Oxman, N., Ortiz, C., Gramazio, F. and Kohler, M. (2015) 'Material ecology', Computer-Aided Design, Vol. 60, pp.1-2.

Oxman, N. and Rosenberg, J. (2007) 'Material computation', International Journal of Architectural Computing, Vol. 1, No. 5, pp.21-44.

Richards, D. and Amos, M. (2014a) 'Evolving morphologies with CPPN-NEAT and a dynamic substrate', in Sayama, H. Rieffel, J. Risi, S. Doursat, R. and Lipson, H. (Eds.): Proceedings of ALIFE 14, the Fourteenth International Conference on the Synthesis and Simulation of Living Systems, MIT Press, New York, 30 July-2 August 2014. pp.255-262. 
Richards, D. and Amos, M. (2014b) 'Designing with gradients: bio-inspired computation for digital fabrication', Proceedings of the 34th Annual Conference of the Association for Computer Aided Design in Architecture (ACADIA), Los Angeles, 23-25 October, 2014, pp.101-110.

Schumacher, P. (2016) 'Parametricism 2.0: gearing up to impact the global built environment', Architectural Design, Vol. 86, No. 2, pp.8-17.

Soldevila, M., Royo, D. and Oxman, N. (2015) 'Form follows flow: a material-driven computational workflow for digital fabrication of large-scale hierarchically structured objects', Proceedings of the 35th Annual Conference of the Association for Computer Aided Design in Architecture (ACADIA 15), Cincinnati, 19-25 October, 2015, pp.1-7.

Tibbits, S. (2012a) 'From digital materials to self-assembly', Proceedings of the 100th Annual ACSA Conference, Boston, MA.

Tibbits, S. (2012b) 'The Self-Assembly Line', Synthetic Digital Ecologies [Proceedings of the 32nd Annual Conference of the Association for Computer Aided Design in Architecture (ACADIA), San Francisco, CA, 18-21 October, 2012. pp.365-372.

Tibbits, S. and Cheung, K. (2012) 'Programmable materials for architectural assembly and automation', Assembly Automation, Vol. 32, No. 3, pp.216-225.

Vogel, S. (2003) Comparative Biomechanics: Life's Physical World, Princeton University Press, Princeton, NJ.

Wiscombe, T. (2010) 'Extreme integration’, Architectural Design, Vol. 80, No. 2, pp.78-87.

Wiscombe, T. (2012) 'Beyond assemblies: system convergence and multi-materiality', Bioinspiration \& Biomimetics, Vol. 7, No. 1, p.015001. 
